\title{
Investigating Arabic Pragmatic Markers in Spoken Discourse: A Literature Review
}

\author{
Yaseen Azi \\ MA in Linguistics/TESL from Indiana State University, U.S.A \\ Ph.D. candidate in Educational Linguistics in University of New Mexico, U.S.A \\ Lecturer of Linguistics in Jazan University, SA \\ E-mail: ezzi1428@gmail.com
}

Received: April 5, 2018 Accepted: April 13, 2018 Published: April 25, 2018

doi:10.5296/ijl.v10i2.12963ＵRL: https://doi.org/10.5296/ijl.v10i2.12963

\begin{abstract}
Generally speaking, the current paper demonstrates a detailed and critical exploration of Arabic pragmatic markers (PMs) in spoken discourse. Although there seems to be less agreement on the topic of the particular phenomena that the current study is addressing, my study will use the term PM instead of discourse marker (DM). For clarity, it should be identified that a PMs in this study is "most commonly used as a general or umbrella term covering forms with a wide variety of functions both on the interpersonal and textual levels" (Zienkowski, Östman, \& Verschueren, 2011, p. 227); therefore, DMs or any other linguistic elements with discourse functions are considered as a subtype of a PM (see Fraser, 2009; Aijmer,2013). Based on the literature review, treating the phenomena as PMs will provide us with a more comprehensive approach towards the study of that particular phenomena in Arabic dialects; such an approach does not only focus on texts, but also incorporates social, cultural, and linguistic aspects of the contexts into our analysis of the phenomena. Briefly, the structure of this paper will be divided into the following sections: a definition of pragmatic markers, theoretical approaches of PMs, PMs in the Arabic literature, variations in Arabic, a variational pragmatic approach and PMs, treatment of PMs in Arabic literature, PMs in Modern Standard Arabic (MSA), PMs in Dialectal Arabic, and conclusion.
\end{abstract}

Keywords: Arabic pragmatic markers, Discourse markers, Spoken discourse, Discourse analysis, Pragmatics, Modern standard Arabic, and dialectal Arabic 


\section{Background of the Study}

PMs, as important linguistic elements, have been studied by many researchers in different languages such as English (e.g. Fraser, 1999; Blakemore, 2002; Schiffrin, 2003; Jucker and; Redeker, 2006), Arabic (e.g. Al-Batal,1994), Hebrew (e.g. Maschler, 1998; Shloush, 1998; Ziv, 1998), Hungarian (Vaskó, 2000), Chinese (e.g. Tsai \& Chu, 2017), Swedish (e.g. Aijmer and Simon-Vandenbergen, 2003) Spanish (e.g. De Fina, 1997). There is still a less agreement on what to be defined as PMs (Yang, 2014).So, linguistic elements that are identified as PMs in this study (Fraser 1988,1990; Schiffrin, 1987) are referred to as pragmatic formatives (Fraser, 1996), pragmatic connectives (van Dijk, 1979; Stubbs, 1983), pragmatic operators (Ariel, 1994), pragmatic particles (Östman, 1995), conjuncts (Quirk and Greenbaum et al., 1985) and sentence connectives (Halliday and Hasan, 1976), discourse signalling devices (Polanyi and Scha, 1983), pragmatic expressions (Erman, 1987), phatic connectives (Bazanella, 1990), cue phrases (Knott and Dale, 1994), discourse connectives (Blakemore, 1987, 1992, 2002), discourse operators (Redeker, 1990, 1991), and particles (Schourup,1985).

Likewise, studies on PMs have revealed that identifying particular theoretical approaches on the study of that specific phenomena is also still a controversial topic in the literature as they vary as much as our definitions, methods of investigations and research interests also vary. When discussing the phenomena in Arabic linguistics, the situation becomes more complex as the term PM is relatively new and has never been used in previous research on Arabic. Instead, terms such as particles, connectives and DMs are extensively used either in studies in MSA or in other Arabic varieties. Further, Arab and Western linguists extensively used terms such as DMs, connectives or particles in their studies on standard Arabic varieties, like Modern Standard Arabic, or in studies on different Arabic dialects.

Therefore, studies on the phenomenon in Modern Standard Arabic (MSA) have more commonly used a term as connectives instead of the other widely used linguistic terms in the literature such as PMs and discourse markers (see Al-Batal, 1985; Ryding, 2006). This indirectly points out to the fact that the functions of those linguistic elements are assumed to be limited to sentence level. As Al-Batal (1985) claims, such linguistic entities in MSA are defined as "coordinating conjunctions, subordinating conjunctions, and subjunctive particles" with functions that are mainly syntactically-based (Al-Batal, 1985, p. 22). Moreover, as Alkholani (2010) indicates, Arabic connectives in Al-Batal's (1985, 1990) works are not presented as linguistic elements with functions at discourse level. Instead, Al-Batal's (1985) and (1990) treatment of those entities, that have functions similar to PMs, is similar to "the traditional sentence-bound treatment of these items of which he criticizes traditional grammarians” (Alkholani, 2010, p. 84).

Furthermore, the other limitation on the phenomena in Arabic linguistics is related to the fact that studies on Arabic PMs with a systematic treatment and functions at discourse level is still at scarce in Arabic literature (Al Kohlani, 2010). So, PMs or even other terminologies such as DMs and connectives are not used in the traditional treatment of the phenomenon in Arabic. Instead, such elements are treated as particles with grammatical functions that only operate 
within sentence boundaries. Besides, even though the modern treatment of the phenomena by the Arab and Western linguists (e.g. AlBatal, 1984, 1994; Ryding, 2005) have added more of a semantically- based analysis to those elements, their treatment of such linguistic entities "continues to be syntactically-oriented and restricted to the sentence limit” (Al Kohlani, 2010, p. 76).

On the other hand, Arabic PMs have been differently treated when they are investigated in dialectal Arabic (see Al-Khalil, 2005; Gaddafi, 1990; Kanakri \& Al-Harahsheh 2013). Therefore, a more semantic-based analysis is now used where new linguistic entities such as ya@ni (I mean), ạrif (I know), tayyeb and Sadi (ok) have been categorized as Arabic PMs with similar functions at discourse level. Nevertheless, the analysis is always centered on the relevance-theoretic approach where the multi-functionality of PMs is ignored and they are accordingly treated as elements with more procedural meanings that are mainly related to the local coherence of the text (e.g. Al-Batal 1994; Hussein \& Bukhari, 2008). Such studies succeeded to demonstrate a semantic analysis, an analytical perspective that was not addressed before in the traditional grammarian studies. However, the analytical framework and the general treatment of Arabic PMs remain similar to the traditional treatment of PM in Arabic literature. 7).

Moreover, according to both the traditional and modern treatments of phenomena in Arabic linguistics either written or spoken discourse, these linguistic elements are treated as only having procedural meanings and syntactic functions, mostly associated with the coherence and cohesion of a text. Likewise, the relevance theoretic approach, that is known as the less compatible approach to the study of PMs (Aijmer, 2013), has been the main analytical approach on the phenomena in Arabic linguistics. This is simply because, according to such theoretical approach, fewer markers can be identified as PMs; only the ones that communicate "procedural meanings" such as but, so and and. What's more, according to the relevance theoretic approach, other markers with conceptual meanings such as frankly and in contrast, that are classified as PMs in other frameworks (i.e., coherence model), are not at all identified as PMs (Yang, 2014, p.12).

In short, approaches that treat those linguistic devices with limited structural functions will fail to account for the multifunctional uses of Arabic PMs in different Arabic varieties. So, to address the previous gab in Arabic literature, this study proposes an analytical framework that treats the phenomena as PMs and also acknowledges the fact that such linguistic elements are considered multi-functional conversational devices that significantly contribute to discourse coherence at different levels (i.e., local and global coherence (see AlMakoshi, 2014; Fung, 2003; Fung\& Carter, 2007; Yang, 2014). Accordingly, the current study contends that treating the phenomena as PMs especially when investigating the phenomena in spoken discourse, will provide us with a comprehensive approach to the investigations of the phenomena from different perspectives, which will also incorporate "variational and sociolinguistic aspects” of PMs (Beeching \& Woodfield, 2015). 


\section{Literature Review}

\subsection{Defining Pragmatic Markers}

Even though the terms pragmatic markers and discourse markers have been used interchangeably, they should be two separate linguistic entities because of their distinctive linguistic functions in written and spoken discourse. When comparing pragmatic markers to discourse markers in terms of their functionality in discourse, pragmatic markers appear to perform a larger number of interactional functions that are mainly related to spoken discourse. On the other hand, discourse markers have been observed to have fewer functions, which are basically related to written discourse. In a brief discussion of the forms and types of pragmatic markers, Fraser (2009) identified four types of pragmatic markers, including 1) basic markers as such as please and I promise 2) commentary markers, such as frankly and certainly; 3) parallel markers, such Sir, damned, and hey; and 4) discourse markers, such as and and but (p. 3-5). However, it should also be indicated that many markers, such as "hesitations," "pauses," and "reformulation markers," could not fit into the previous categories because having one unified list of pragmatic markers and identifying a straightforward definition of these markers are still controversial issues in the literature (Brinton \& De Gruyter, 1996, p. 32).

In her detailed study, Pragmatic Markers and Sociolinguistic Variation, Andersen (2001) clearly differentiated between discourse markers and pragmatic markers by citing Brinton's study (1995) of pragmatic markers, in which such markers were described as a "heterogeneous list of forms" (p. 21) mainly used in communications, highly frequent, stylistically stigmatized, and negatively evaluated. Also, these forms, which are discursively "optional” and "multifunctional," are observed to "have no propositional meaning” and "no clear grammatical function” (p. 21).

Moreover, Anderson (2001) argued that her preference for the term pragmatic markers over discourse markers is related to the fact that discourse markers are a "subtype" of pragmatic markers and have "a narrower meaning" in which it is mainly considered as "an expression which signals the relationship of the basic message to the forgoing discourse.” In other words, when comparing the functions of discourse markers to those of pragmatic markers, it can be observed that the functions of discourse markers are mainly related to the "textuality and coherence" of a text, whereas pragmatic markers have various functions that cannot be limited to the same basic functions of discourse markers (p. 40).

In a more detailed description of pragmatic markers, Zienkowski et. al (2011) have identified phonological, lexical, syntactic, semantic, functional, sociolinguistic, and stylistic features for pragmatic markers, particularly in conversations:

- Phonological and lexical features: These are short and phonologically reduced, form a separate tone group, and are marginal forms, so they are difficult to place within a traditional word class.

- Syntactic features: These are restricted to the sentence-initial position, occur outside the syntactic structure or are only loosely attached to it, and are optional. 


\section{Macrothink}

International Journal of Linguistics

ISSN 1948-5425

2018, Vol. 10, No. 2

- Semantic features: These have little or no positional meaning.

- Functional features: These are multifunctional, operating on several linguistic levels simultaneously.

- Sociolinguistic and stylistic features: These are a feature of oral rather than written discourse, appear very frequently, are stylistically stigmatized, gender specific, and more typical of women's speech (p. 226).

To sum up, having one unified list of PMs and identifying a straightforward definition of these markers are still controversial issues in the literature (Aimer, 2013; AlMakoshi, 2014; Fung, 2003; Fung \& Carter, 2007; Yang, 2014). Nevertheless, from the previous discussions of definitions of PMs in the literature, this study proposes the following characteristics and the defining criteria of what candidates that are to be identified as PMs in the current study:

1. In a way that aligns with Schiffrin's (1987) Fung's (2003) and Fung and Carter's (2007) characterization of what is to be classified as PMs (DMs in their terminology), I consider multi-functionality at the local and global discourse level, semantic and syntactic independency and orality the general defining features of PMs in the spoken discourse.

2. PMs are more frequently used in the initial position (Schiffrin,1987). Yet, they are optional as they can be added to any position of an utterance in the structure. (i.e. initial, internal, or final position).

3. Adding or removing PMs does not affect the grammaticality or the propositional of a sentence (Schourup, 1999; Fung, 2003; Müller, 2005).

4. As Schourup (1999) pointed out, PMs "actually "display", "reinforce”, or "clue" the intended interpretation rather than "create" additional meaning" (as cited in Yang,2014, p.23).

5. Similar to Schiffrin's treatment of such entities, PMs in this study are treated as elements with core meanings (at the macro-level) and various functions (micro-level) that change from slot to another in discourse (Schiffrin, 1987, p. 318). By 'slots,' I mean the macro functional levels of discourse on which PMs function.

\subsection{Theoretical Approaches to the Study of Pragmatic Markers}

Generally speaking, PMs have been investigated within a large number of theoretical approaches that vary as much as their definitions, research methods and research interests of those linguistic elements also vary. Therefore, it might not be possible to present a complete review of all the approaches that have been proposed towards the study of PMs. However, when looking at the literature on PMs in the spoken discourse, the discussions and the analysis of PMs center on three main approaches: the discourse approach, the semantic approach and the relevance-theoretic approach (Feng, 2010, p.166). Thus, in what follows, a focus discussion of these three approaches will be presented. 


\subsubsection{Discourse Approach}

As for the first approach, the discourse approach, the general underlying assumption of that approach is that discourse is coherent in nature. Briefly, when looking at the literature on PMs through the discourse approach in terms of discourse analysis, such linguistic elements are usually studied and analyzed mainly through two theoretical frameworks: Halliday's and Hasan's (1976) systemic functional approach and Schiffrin (1987) discourse coherent-based model. According to the systemic functional approach, cohesion of discourse "is not the presence of a particular class of items that is cohesive, but the relation between one item and another" (Halliday and Hasan, 1976, p 173). Moreover, in that particular approach, PMs are not identified as the devices of text coherence. Instead, cohesion of a text is achieved through categories such as co-reference, substitution, conjunction, ellipsis and lexical cohesion (Feng, 2010, p. 168).

Halliday and Hasan's (1976) approach is not concerned with PMs as Shiffrin (1987) model. However, the systemic functional approach is presented in this study because "it has provided future researchers with a semantic classification" of PMs which is known to have a significant influence on Shiffrin (1987) coherence model; the most highly cited theoretical framework on PMs from the last three decades till present. Interestingly, Shiffrin is considered "the first scholar to take a consistent interest in and investigated English pragmatic markers as a class" (Feng, 2010, p. 169). Further, the strengths of Shiffrin's (1987) model lies in the fact that it offers both macro and micro linguistic analysis that accounts for "the use and the distribution of markers in everyday discourse” (Shiffrin, 2001, p. 58).

Shiffrin's (1987) model is a corpus-based approach that is originally based on the corpus-based analysis of the uses and functions of 11 English PMs: oh, well, and, but, or, so, because, now, then, I mean, and you know. The coherence-based model offers a more functional analysis, similar to Halliday and Hasan's (1976) functional approach (Feng 2010). Thus, according to her approach, Shiffrin (1987a) defines PMs as "sequentially dependent elements which brackets the units of talk" (p. 31) and also function as "discourse glue” providing the structure and coherence of the text. Furthermore, PMs in Shiffrin's model, are defined as "a set of linguistic expressions comprised of members of word classes as varied as conjunctions (e.g. and, but, or), interjections (oh), adverbs (now, then), and lexicalized phrases (y'know, I mean)" (Schiffrin, Tannen, \& Hamilton, 2001, p.57).

PMs, according Shiffrin's (1987) coherence model, can function at five discourse planes that helps establish coherence relations between units of discourse (p. 9). That multi-planed discourse model shows how discourse coherence is locally and globally achieved through the multi-functions that PMs simultaneously perform at those five discourse planes:

- Participation Framework refers to the different interactional process through which speakers and hearers can get involved through talk due to their mutual presence and shared responsibility for discourse and its production.

- Information State involves the organization and management of the knowledge and the meta-knowledge possessed by participants. 


\section{Macrothink}

International Journal of Linguistics

ISSN 1948-5425

2018, Vol. 10, No. 2

- Ideational Structure deals with semantics structures. Three different relations where semantic structures contribute to the overall configuration: cohesion, topic and functional relations.

- Action structure deals with speech acts in terms of what action proceeds, what action is intended to follow and what action actually does follow.

- Exchange Structure is the process through which interlocutors can alternate sequential roles and define those alterations in relation to each other (24-28).

As can be observed above, Schiffrin's (1987) five-plane model shows how the different planes of discourse are interconnected. Through adjacent units in discourse, local coherence is constructed. In term of global coherence, the same model "can be expanded to take into account more global dimensions of coherence" (Schiffrin, 1987, 24). Although the PMs she examined in her study are based on the planes of discourse on which they function, PMs can have functions on more than one plane (Schiffrin, 1987, 316).

However, Schiffrin's (1987) coherence model has been criticized as its theoretical and operational identification of PM is considered too broad to identify what to PMs are (Fraser, 1999, Redeker, 1999). Based on that, other criteria are proposed by the same researchers. Yet, their criteria were also problematic. For instance, according to Fraser's (1999) problematic definition of PMs, linguistic elements such as now, I mean, yknow are not considered PMs. Similarly, Redeker (1991) criticizes the fact that no specific identification of what to be identified as PMs are provided in the coherence model. Further, she also claims that Schiffrin's proposed-planes, information structure plane and participation plane, are not as equal as the other three planes and that is because they are related to cognition and attitudes which are better seen as "contributing indirectly to coherence by choices at the pragmatic plane” (Redeker, 1991, p. 1162). Despite the fact that Redeker proposed another framework, her work does not significantly vary from the coherence model in which it is considered as "rough equivalents to Shiffrin' (1987) ideational and action structures and an extended variant of her exchange structure” (Fung, 2003, p. 47).

\subsubsection{The Semantic Approach}

Another popular approach on the study of PMs-the semantic approach- is demonstrated in Fraser's works (1990, 1995, 1996, 1999, 2006). According to Fraser (1999, p. 931) PMs are:

"a class of lexical expressions drawn primarily from the syntactic classes of conjunctions, adverbs, and prepositional phrases [which] signal a relationship between the interpretations of the segment they produce”

In a brief discussion of the forms and types of PMs, Fraser (2009) identified four types of PMs, including 1) basic markers as such as please and I promise 2) commentary markers, such as frankly and certainly; 3) parallel markers, such Sir, damned, and hey; and 4) DMs, such as and and but (p. 3-5). Although Fraser's approach has significantly contributed to the analysis of PMs in terms of the comprehensive typological classification of PMs, I think the main limitation of his work is in his categorical identification of PMs where many markers 
cannot be classified as PMs in his definition such as "hesitations," "pauses," and "reformulation markers."

Therefore, in a detailed discussion of Fraser's work, Yang (2014), argues that “different from Schiffrin (1987), PMs, in Fraser's (1999) definition, are only limited to linguistic words that signal adjacent discourse segments” (p.12). She also added that although both Schiffrin and Fraser agree that PMs have core meanings in relation to the context, Fraser's approach treats PMs as elements with procedural meanings rather than conceptual meanings. This particular treatment of PMs aligns with the relevance theorists' argument of the non-truth-conditionality feature of PMs where such linguistic entities are considered elements that do not significantly contribute to meanings (e.g. Blakemore, 1996). However, due to Fraser's (1999) treatment of PMs that involves procedural and conceptual meanings of PMs leading accordingly to "a mismatch between definition and classification” (Yang. 2014, p. 12) such approach has not been widely used by researchers on PMs.

\subsubsection{The Relevance Approach}

Another highly cited approach on the study PMs is Blackmore's (1987) relevance theoretic approach which has been extensively used by the Arab linguists in their studies on Arabic PMs in the spoken discourse. By and large, the relevance theory was developed to account for the discourse approach and challenge their views that classify PMs as linking devices. Therefore, according to the relevance theory advocates, the functions of PMs are not "to glue discourse, but rather guide the hearer to the intended interpretation of the utterance and thus facilitate utterance interpretation” (Feng, 2010, p. 172). According to this approach, PMs are "expressions that constrain the interpretation of the utterances that contain them by virtue of the inferential connections that they express" (Blakemore, 1987, 105). Accordingly, what to be identified as PMs are only elements such as but, so, and with "procedural meaning" but other other markers with conceptual meanings like frankly and in contrast (Yang, 2014, p.12). Likewise, in Blakemore's (1992) view, PMs that encode conceptual meaning such as ' $a$ s a consequence' and 'contrary to expectations' are not classified as PMs as they do not encode a procedural meaning.

However, the relevance theory is seen as the least compatible approach to the study of PMs especially in the spoken discourse and not adequate to describe the multi-functions of PMs in interactions. This is simply because it mainly relies on the contextual assumptions in the interpretation of the various functions of PMs and “doesn't take 'an integrated view' on how utterance meaning is achieved” (Aijmer, 2013, p. 11). So, as Aijmer (2013) points out, an analysis of PMs that mainly relies on "finding a common principle" ... "on the basis of contextual assumptions" (p. 11) will not provide an adequate interpretation of the various pragmatic functions of those elements that vary according to the text type and the actual role of language user in interactions. According to this theory, "a number of linguistic and contextual factors on the use of discourse particles are understated" (Lam, 2009, p. 354). Such an obvious limitation makes the relevance theory an incomprehensive approach for analyzing the whole of the interactional processes related to "a particular culture, or society, religion, social situation, historical period, etc.” (Aijmer, 2013, p. 12). 


\subsection{Variations in Arabic}

Because of the complex diglossic phenomena and the diverse spoken and written varieties of Arabic, the lists of DMs in the Arabic language, particularly in the different colloquial Arabic dialects, are supposed to be structurally various and functionally complex. According to Ibrahim (2009), variation in Modern Standard Arabic has been shown to exist not only in different phonological, morphological, and syntactic forms of the language, but also at the lexical levels of the language. According to the findings of different studies on variations in Arabic, the cases of linguistic variations at the different levels are expected to increase dramatically in the future. Thus, with that in mind, the validity and reliability of the current approaches toward the study of connectives, as Arabic DMs, are highly questionable and problematic. As discussed earlier, based on the traditional and modern approaches toward the study of DMs, the occurrences and functions of Arabic DMs are assumed to be limited to standard Arabic varieties like Modern Standard Arabic or Classical Arabic (Al Kohlani, 2010). Therefore, studying Arabic DMs mainly from such a narrow window will deprive us of investigations into how the phenomena appeared in other sociocultural contexts, and how their forms and uses vary in different non-standard varieties of Arabic. Accordingly, I strongly believe that adopting the theoretical approaches of PMs, such as the interactive model, toward the study of the Arabic PMs will enable us to investigate how linguistic elements like connectives and particles are socially and pragmatically used in the various spoken varieties of Arabic.

Thus, PMs should not be treated as linguistic utterances that are "discursively optional and have on oppositional meaning” (Andersen, 2001, p. 21). Instead, I think PMs are communicative devices with functions that are "socially, culturally and linguistically embedded in the context” (Aijmer, 2013, p. 9). In other words, PMs are complex linguistic productions communicating a variety of functions; they are greatly influenced by social, cultural, and regional factors. Understanding the different functions of PMs requires having a more comprehensive approach to the analytical study of these phenomena. Interestingly, as will be briefly presented in the next paragraphs, a possible approach has been proposed by Aijmer (2013) in her discussions of the variational pragmatic approach.

\subsection{Variational Pragmatic Approach and PMs.}

Through her discussions of the current theories of PMs, along with their strengths and weaknesses, Aijmer (2013) has shown how Barron and Schneider's theory of variational pragmatics (2009) provides an adequate approach to the detailed investigations of PMs in different contexts. Even though the main principles of the variational pragmatic approach were initially introduced by Barron and Schneider (2009), Aljmer (2013) has developed a good description of that approach in the analysis of PMs presented throughout the different chapters of her book. In her discussions of pragmatics from a variational perspective, Aijmer (2013) has introduced reflexivity and contextualization cues as crucial characteristics of PMs. Starting with reflexivity, according to Verschueren 1999 (as cited in Ajmer, 2013), reflexivity is defined as "the speaker's awareness of the linguistic choices made both with regard to what to say and how to say it” (p. 4). By associating PMs with reflexivity, a more appropriate 
definition of PMs can be made to allow various linguistic features such as prosody, hesitation, pausing, and larger lists of markers and particles to be identified as PMs establishing the overall "coherence of the discourse" (p. 5). Contextualization cues, on the other hand, are also important to our understanding of PMs, in which they function as indicators of the fluidity of the interactional processes of PMs in the different types of discourse (p. 6).

According to Aijmer's (2013) variational pragmatic approach, multi-functionality is a core feature of a PM. For instance, so, now and well are good examples of the multifunctionality of PMs. "So", and "now", as interactional devices, have multiple interactional functions "in summarizing, marking boundaries of talk, switching topic, establishing consequences, etc." (Fung \& Carter, 2007, p. 413). Likewise, well also performs a wide variety of pragmatic functions such as self-repair, turn taking device, marker of disagreement, marker of politeness and face saving, etc, (Aijmer, 2013). Thus, when analyzing the various functions of such linguistic elements in a text, "the status of a (PM) needs to be contextuallyreferenced (p. Fung \& Carter, 2007, p. 413).

Now after presenting and discussing the previous studies of PMs, including the leading works of Aijmer (2013) and for the specific interest of this paper focusing on Arabic PMs in the spoken discourse, it is more appropriate then to move to the last part of the literature review which mainly discusses PMs in different colloquial dialects of Arabic. Also, it should be clearly noted that studies on the phenomena that is going to be discussed in the last part of this paper have used the term DMs instead of PMs. My count here is that I don't only oppose to these authors' treatment of the phenomena as DMs, but also to their incomprehensive approaches toward the study of the phenomena.

\subsection{Arabic PMs in the Spoken Discourse}

In this section, a more focused exploration will be centered on the phenomena- that is- Arabic PMs in the spoken discourse. So, a brief presentation will be demonstrated to identify how such linguistic entities are treated in the Arabic literature. Also, a detailed discussion will be provided to show what PMs are used in Modern Standard Arabic (MSA) and dialectal Arabic and how they have been studied in those different Arabic varieties.

\subsubsection{Treatments of PMs in the Arabic Literature}

In a discussion of PMs in Arabic and how they were investigated in different studies, $\mathrm{Al}$ Kholani (2010) stated that PMs have been treated differently in the literature where two main treatments can be identified: traditional treatment and modern treatment. First, the traditional treatment of PMs, by previous generations of Arab grammarians, does not even treat the phenomena as PMs or even as DMs with functions at discourse level. Instead, an Arabic term Huruf (Harf sg.) "particles," which are defined as "words that only make sense when joined with others," (King 1992, 260) was used and the functions identified are only structurally based that are limited to sentence level. The modern treatment has been introduced by Western and Arab linguists in their presumably modern linguistic studies of Arabic. However, their treatment of Arabic PMs "continues to be syntactically-oriented and restricted to the 
sentence limits. The treatment of DMs as linguistic items functioning at the discourse level, therefore, is almost absent in modern linguistic studies of Arabic” (p. 76-78).

For clarity, it should be clearly stated that although I agree with Al Kholani's previous argument of the traditional treatment of Arabic PMs in the literature, I found her argument of modern treatment is not entirely valid. As will be presented in the two sections below (2.5. 2 \& 2.5.3), fewer recent studies in Arabic literature have demonstrated a complex discourse analysis of the phenomena identifying a variety of functions at discourse level (e.g. Alshamari, 2015; Bidaoui, 2015; Gaddafi, 1990; Kanakri \& Al-Harahsheh,2013).

\subsubsection{PMs in Modern Standard Arabic}

In their studies on PMs in MSA, Al-Batal (1985) and Ryding (2006) have used the terms connectives instead PMs or even the widely used term DMs, and that indirectly points to $\mathrm{Al}$ Kholani's (2010) previous argument that the functions of those linguistic elements are assumed to be limited to connecting utterances at sentence level even in modern treatment. According to Al-Batal (1985), PMs in MSA are defined as "coordinating conjunctions, subordinating conjunctions, and subjunctive particles" with functions that are mainly syntactically-based (al-Batal, 1985, p. 22). A similar definition of the same phenomena has been also found in Ryding's (2006) chapter on Arabic connectives. Thus, in her comparison of the uses of PMs in English with those in MSA, the Arabic PMs (DMs in her terminology) are described only as connectives that are "structurally fixed" with functions mostly limited to texts, whereas the English PMs are seen to have a larger list of functions that can be both conversationally and textually based (Ryding, 2006, p. 407-408).

Furthermore, in a detailed discussion of the forms and the functions of connectives, Ryding (2006) stated that connectives in MSA have different forms and functions that are directly related to their structural roles in texts; therefore, connectives can have a broad list of forms, including "conjunctions, adverbs, particles, and also certain idiomatic or set phrases," and their functions in texts are either to connect a "phrase, clause, sentence, [or] paragraph," or to organize and introduce "text elements, and others requiring particular grammatical operations.” However, Ryding argued that it is only simple linking connectives, rather than operative particles, that should be regarded as Arabic connectives with functions similar to PMs (DMs in her study) (p. 409).

Additionally, according to Ryding (2006), the simple linking connectives are divided into eight types, including waaw al-atf, faa al-sababiyya, contrastive conjunctions, explanatory conjunctions, resultative conjunctions, adverbial conjunctions, disjunctives, and sentence-starting connectives (p. 409-421). In the table below (see Ryding, 2006, p. 409-421), examples of the previous types and functions will be concisely demonstrated: 
Table 1. The Eight Types and Functions of Arabic PMs in MSA (Ryding, 2006, p. 409-421).

\begin{tabular}{|c|c|c|c|c|}
\hline $\begin{array}{l}\text { Types \& } \\
\text { Functions }\end{array}$ & $\begin{array}{l}\text { 1.waaw al-atf "and" } \\
\text { 1.sentence starter wa } \\
\text { 2.coordinating } \\
\text { conjunction wa }\end{array}$ & 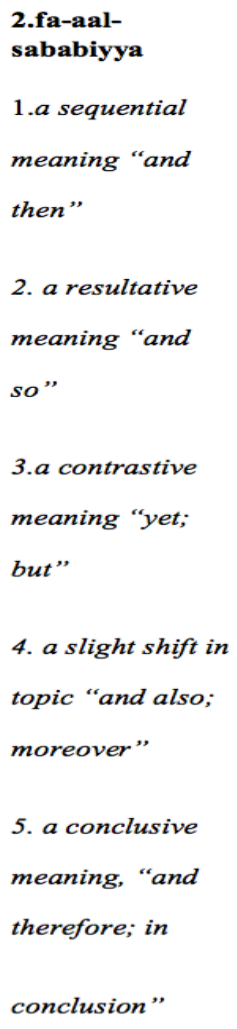 & $\begin{array}{l}\text { 3.Contrastive conjunctions } \\
\text { 1 bal "rather; but actually" } \\
\text { 2. inna-maa, wa-inna- } \\
\text { maa "but; but moreover; } \\
\text { but also, rather" }\end{array}$ & $\begin{array}{l}\text { 4.Explanatory } \\
\text { conjunctions } \\
\text { 1. ay "that is" }\end{array}$ \\
\hline
\end{tabular}

\begin{tabular}{|c|c|c|c|}
\hline $\begin{array}{l}\text { 5.Resultative } \\
\text { conjunctions } \\
\text { 1.idh "since, } \\
\text { inasmuch as" } \\
\text { 2.idhan "therefore" } \\
\text { 3. Hattaa "until" }\end{array}$ & $\begin{array}{l}\text { 6.Adverbial } \\
\text { conjunctions } \\
\text { 1.Place: Hayth-u } \\
\text { "there" } \\
\text { 2.Time } \\
\text { bayn-a "meanwhile; } \\
\text { whereas" bad-a- } \\
\text { maa"after"bad- } \\
\text { an"after" bad-a-idhin } \\
\text { "after than" } \\
\text { Hiin-a-maa and Hiin-a } \\
\text { "when; at the time } \\
\text { when" } \\
\text { ind-a-maa } \\
\text { "when; at the time } \\
\text { when" } \\
\text { ind-aidhin } \\
\text { "then; at that point in } \\
\text { time; at that time" } \\
\text { 3.Subjunctive: } \\
\text { qabl-aan } \\
\text { before" } \\
\text { thumm-a } \\
\text { "then" } \\
\text { 4.Similarity: ka-maa } \\
\text { "as" } \\
\text { mithl-a-maa "like" } \\
\text { mithe } \\
\text { 5.Equivalence } \\
\text { qadr-a-maa } \\
\text { as much" } \\
\text { 6.Reference or }\end{array}$ & $\begin{array}{l}\text { 7.Disjunctives } \\
\text { 1.Inclusive:aw } \\
\text { "or" } \\
\text { 2. Exclusive: } \\
\text { am "or" } \\
\text { "whether... or" } \\
\text { immaa...aw } \\
\text { "either...or" }\end{array}$ & 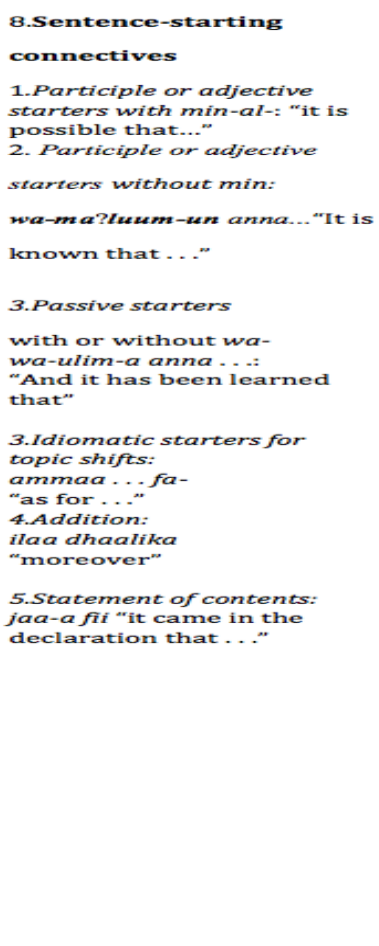 \\
\hline
\end{tabular}




\section{Mll Macrothink}

International Journal of Linguistics

ISSN 1948-5425

2018, Vol. 10, No. 2

The previous table briefly identifies the eight common types and functions of simple linking connectives in MSA. In the following, some examples of the first two types will be briefly presented. The first type, waaw al-atf, is used to "signal an additive relationship" (as cited in Ryding, 2006, p. 409) and it can be used either "a sentence starter" or "a coordinating conjunction” as the following examples: (see Ryding, 2006, p. 411).

\section{(1) Sentence starter wa}

wa-ghaadar-a l-qaahirat-a ams-i musaafiid-u waziir-i l-difaafi-i . . .

(And) the assistant minister of defense left Cairo yesterday . . . is conjunction wa-išpermawaadd-u adabiyyat-un wa-lughawiyyat-un wa-taariixiyyat-un wa-falsafiyyat-un literary, linguistic, historical, and philosophical materials

faa al-sababiyya, the second type, can have different uses and meanings that include 'sequential meaning 'and then,' a resultative meaning 'and so' (faa al-sababiyya), a contrastive meaning 'yet; but,' a slight shift in topic 'and also; moreover', or a conclusive meaning, 'and therefore; in conclusion” (Ryding, 2006, p. 410). Examples of this type will be demonstrated below: (see Ryding, 2006, p. 411)

\section{(2) Sequential Meaning}

fataH-tu l-baab-a fa-nfataH-a.s[epi] opened the door and [so] it opened. 2.2 Resultative meaning

fataH-tu l-baab-a fa-nfataH-a.s[epi] opened the door and [so] it opened

(3) Contrastive meaning Yet they are still interested in the events of the uprising.

As demonstrated in the table above, according to Ryding (2006), only simple linking connectives, rather than operative particles, should be regarded as Arabic connectives with functions similar to what is classified in this study as PMs. It is true that the functions of simple linking connectives are generally related to the structural coherence of texts. However, I strongly argue that the list of PMs in Arabic cannot be limited to those simple linking verbs and the the functions of those elements in the table above similarly cannot be restricted to text level as they also can function at discourse level.

Moreover, according to Ryding's (2006) classification, linguistic elements in Arabic that are known as the operative particles, such as "Inna" which means "verily," cannot be classified as connectives, DMs nor as PMs as they never have functions similar to those elements. Yet, there have been instances during which operative particles perform various pragmatic functions similar to the other PMs and can consequently be treated as PMs. For example, in Saudi Arabic dialects, the operative particle Inna is combined with another particle fi to form one lexical word fiinna, which means "smoothing wrong is going on," however, it might have different pragmatic meanings that vary according to the context.

Based on the previous example of fiinna, investigating Arabic PMs from an approach that treats those different linguistic elements with functions only restricted and fixed to texts will 
not succeed in exploring and finding out other functions that are not embedded in texts. Therefore, a different approach is needed-one that treats the previous linguistic elementsconnectives, conjunctions, particles, or DMs- as PMs with functions embedded in interactions and language use. In other words, treating those linguistic elements as PMs will allow us to investigate the phenomena not only at textual levels, but also in other interactional social contexts. For that particular reason, I find that describing and identifying those elements as PMs, particularly in Arabic spoken discourse, provides us with a macro-linguistic approach to the study of such phenomena; using this approach, other important parameters, such as the whole interactional process, as well as the social and cultural contexts of the linguistic elements, will be incorporated into the body of this analysis.

Accordingly, it should not be surprising to know that some Arab linguists controversially claimed that what to be identified as PMs only exist in Colloquial Arabic but not in Standard Arabic (Al-Khalil, 2005, p. 31). Contrary to Al-Khalil’s claims, Hussein and Bukhari (2008) argues that Arabic PMs are used in standard and non-standard Arabic. Therefore, the findings of Hussein and Bukhari's (2008) have study revealed that linguistic elements in MSA can also function as PMs such as the Arabic PM fa that has been used as PM to encode five different procedural meanings: conclusive import, temporality, explicative force, unexpectedness ( $\mathrm{p}$. 10-14). Al-Khalil's (2005) argument of excluding the phenomena of PMs from Standard Arabic might be motivated by the fact that Classical Arabic (CA) and MSA are highly preserved by Arab speakers in which such varieties of Arabic are known to have limited functions that are related to the religious and official sects. However, that should not be taken for granted to describe CA and MSA as frozen varieties of Arabic where PMs do not occur.

With that being said, the validity and reliability of the current approaches toward the study of the phenomena in Arabic spoken discourse are highly questionable and problematic. As discussed earlier, based on the traditional and modern approaches toward the study of PMs in Arabic, the lists of what to be identified as PMs are assumed to be limited and similarly with functions restricted to sentence level but not to discourse level (e.g. Abbâs, 1963; al-Batal, 1985,1990; 1994; Alsayyid, 1968; Rida, 1961, Ryding, 2006). Studying the phenomena mainly from such a narrow window will deprive us of investigations into what other linguistic elements that are to be identified as PMs based on their discursive functions and how the phenomena of Arabic PMs are actually used in other contexts as the classroom context, which is the focus of this proposal. Accordingly, I strongly believe that treating the phenomena as PMs will enable us to investigate what linguistic elements, not identified in the literature, can be treated as Arabic PMs and what functions they perform in different contexts.

Now after briefly presenting and discussing the treatments of PMs in Arabic literature and particularly in MSA, a presentation of PMs in different colloquial dialects of Arabic will be demonstrated in the next section. It should be clearly noted that studies on the phenomena that is going to be discussed in the coming section have used the term DMs instead of PMs. My count here is that I don't only oppose to the treatment of the phenomena as DMs, but also to the extensive reliance on the relevance theoretical approach to the study of the phenomena in the spoken discourse, an approach that has been identified as the least compatible approach on the study of PMs (Aijmer, 2013). 


\subsubsection{Arabic PMs in the Spoken Dialectal Arabic}

Gaddafi's (1990) study on Arabic PMs in Libyan Arabic is considered the first study on Arabic PMs in the spoken discourse. Interestingly, this is one of the fewer studies in the Arabic literature with analytical framework that is based on Schiffrin's (1987) coherence model. Based on naturally collected data through participant observation, the previous researcher investigated the uses and functions of some Arabic PMs including Caraft (you know), Saraft keif ('you know how), ta9rif (you know) and yaSni (I mean) and others causality markers such as lihada, idan, which literally means (so), and lianna that means (because) .Briefly, the purpose of Gaddafi's study was to analyze the multiple interactional functions of the previous PMs in spoken Libyan Arabic from an analytical frame that is based on Schiffrin's (1987) five functional planes: exchange structures, action structures, ideational structures, participation framework and information state (see section 2.5.1 for a detailed discussion of the five planes).

In short, the findings of Gaddafi's (1990) study demonstrated that the use of Schiffrin's (1987) model as an analytical approach provided a detailed analysis. For instance, the markers Garaft (you know), Saraft keif (you know how) and ta९rif (you know "female marker") were used to perform multiple interactional functions at different discourse levels particularly at exchange structures and information state levels, whereas ta9rif and Saraft keif were more likely to function at the level of participation frameworks (p. 142). The PM ya?ni "I mean” performed three main functions related to the participation frameworks: "a marker of explanation of intentions, a marker of expansion of ideas and a marker of replacement repairs” (p.201). On the other hand, markers of causality as lianna "because", idan "so" were used "to mark factbased causal relations (while)... idan (was) used to mark knowledge-based causal relation in the information state." lianna "because" was used "to mark action-based causal relations". And finally, lihada, and idan were used to promote turn-transition” (p. 272-273).

Furthermore, based on a spoken corpus collected from TV and radio programs and recorded interviews, Batal (1994) explored the uses and functions of some Lebanese Arabic (LA) PMs including ya?nī “i mean,” bass “ but," halla "now," tayyeb “well,” and ba‘a "so" and therefore." The findings of his study demonstrated that the Arabic dialectal PMs in his study function at both sentence level and discourse level (94-97). For example, the Arabic PM yani, in a way similar to the English PM in other words, functions at a clause and a paragraph level to denote clarification and recap similarities. At a discourse level, the same marker, is used as discourse filler with functions similar to you know and I mean in English. While the Arabic PM bass (but) is used to point out an adversative relationship between elements in the text, halla (now) is used to imply a shift in the movement of discourse and to change a discourse topic. Similar to so and therefore in English, Ba'a is used to indicate a conclusive relationship between two elements of discourse. Tayyeb (well) implies a shift between speakers in discourse.

Moreover, the second type of Arabic PMs in Al-Batal's (1994) study were Arabic PMs that are common to LA and MSA such as wa (and), aw (or), la-'innu, 'izzan, leekin, and ma' 'innu. According to Al-Batal (1994), wa and aw are classified as connectives; the first marker indicates an additive relationship between discourse units, while the second marker denotes an 
alternative relationship. La- 'innu (because) implies causal relationship in discourse. Izzan (therefore, thus) suggests a conclusive relationship. The Arabic PMs Leekin (but) and ma innu (although) indicate adversative relationship.

The third list of Arabic PMs in Al-Batal's (1994) includes markers that are more commonly used in MSA such as fa, Ada San inn "in addition," bi-l-idaafe li "in addition to," fadlan Yan "in addition to," innama "but; but rather," kazalek "likewise, similarly," and amma and 'ay "that is; i.e." amma...,fa.... "as for...,..." . Fa is considered the most complex Arabic PM as it communicates different functions such as implying causal and conclusive relationships (= so and therefore) and introducing topic comments (=so far). Other PMs such as 'Ada Yan inn,bi-l-idaafe li, fadlan San similarly function as indicator of additive relations in discourse. 'Innama (but, but rather) are used to denote adversative relationship. Ay is used as explicative marker. While Amma is used to introduce new topic, fa is added to introduce the comment.

Although Al-Batal (1994) claimed that his analysis is not similar to "sentence-based approach that has dominated the study of connectives in Arabic grammar does not adequately account for their complex textual functions” (p. 92), the findings of his study revealed more of a sentence level-based analysis-an analysis that treats PMs as connectives with functions limited to text coherence. By adopting the relevance analytical framework that treats PMs as elements with more procedural meanings, Al-Batal's interpretations of the functions of Arabic PMs in his study mere mainly limited to the local coherence of the text where PMs have more of structural functions. So, with that being said, it should not be surprising to know that other important functions of PMs that are related to the global coherence are not addressed in that study (i.e. interpersonal functions).

Likewise, based on relevance-theoretic approach and sociolinguistic theoretic model, Bidaoui's (2015) investigated the uses of some Arabic PMs in three Arabic dialects. He hypothesized that different social variables like nationality and type of interaction, as well as individual choices accompanied by differences among the dialectal systems of the participants will lead to variations in the use of PMs of elaboration among participants in his study. Twenty-four males aged 25-56 participated in the study; they spoke three different Arabic dialects: Algerian Arabic, Moroccan Arabic, and Egyptian Arabic. Through interviewing the participants and observing two types of conversations, interactions between people of the same and different nationalities, the researcher collected data from 12 conversational sessions of thirty minutes each and from 21 sessions of structured interviews of twenty minutes each.

The findings of Bidaoui's (2015) study revealed that variations in the uses of the same markers occur-particular markers were only used in particular dialects. Briefly, these were the PMs that were used by the participants: ya@ni /yə̊ni, za Sma, C'est a dire, je veut dire, ça veut dire, which they literally mean "I mean" (p. 27). Linguistic elements like yaSni and yəSni were used by all three dialects. On the other hand, za Sma was only used between participants of the same nationality, such as a Moroccan talking to another Moroccan, or an Algerian talking to an Algerian. The French PMs C'est a dire, je veut dire, ça veut dire only appeared in the Algerians' and the Moroccans' speech. 
Through the relevance-theoretic approach, Bidaoui (2015) was able to investigate different pragmatic meanings of Arabic PMs, which were not possible in the previous studies. Further, in contrast to the previous studies on PMs in MSA where Arabic PMs are treated as connectives with functions limited to coherence of the text, Bidaoui demonstrated a different sociolinguistic- based analysis of PMs in three spoken Arabic dialects through exploring the impact of important social variables such as nationality and types of interactions on the uses of PMs, which is still an area that has not yet been enough addressed in the Arabic literature.

However, treating the phenomena from the relevance-theoretic approach has posed certain problematic issues. According to Bidaoui's (2015) relevance analytical approach, an important multifunctional marker such as yaSni was only identified as marker with no conceptual meaning. According to that, other important contextual components that constitute the multi-functional uses of clarifications markers are missing in Bidaoui's analysis where the functions were only analyzed from a general principle, the principle of relevance to the hearers. Thus, I found the identified functions of those elements, especially clarifications markers (i.e., yaYni), in the researcher's work do not answer important questions related to why these PMs are used interactions (Aijmer, 2002). Further, because of his identification of some PMs as elements with procedural meanings and with functions parallel to those of the grammatical categories, Bidaoui associated himself among the Arab linguists whose approaches align in their treatment of phenomena in Arabic where such elements are treated as connectives and particles with textual functions.

Through using discourse analytical approach and translation theory as theoretical frameworks of their analyses and based on a 20 video-taped dyadic Jordanian Arabic conversations, Kanakri and Al-Harahsheh (2013) studied the uses and functions of the dialectal Arabic PM Pa:di "ok,"a PM that has been widely investigated in the literature. Findings revealed the Arabic PM Ra:di was used to perform nine pragmatic functions as identified below:

- to support or extenuate a difficult situation.

- to ask for a permission to do something.

- to communicate disapproval or rebuke.

- to show discontent of certain incidents.

- to express the meaning of contempt, disdain, or scorn.

- to express courtesy.

- to show an acceptance of but without bearing any responsibility taking an action.

- to save one's face.

- to express an indirect interrogation or criticism of a certain behavior (p. 61-62).

Based on the transcriptions of seven Egyptian movies, Ismail (2015) demonstrated another qualitative analysis of the functions of three Egyptian markers "ba'a”, "țayyeb”, and "ṭab" which literary mean "ok." The results of his analysis showed that "ba'a” performs the following functions: "coherence, contrast, end of encounter, conclusion, interpersonal management, end of patience, surprise, sarcasm or politeness” (p. 57). Although tayyeb and tab have different spellings, they have almost the same meanings. Therefore, tayyeb and tab 
are commonly used as response tokens with similar functions related to acknowledgment, giving consent, mitigating, a directive speech act and threatening (p. 70).

PMs have also been explored in the Saudi Arabic. An example of that is Alshamari's (2015) pilot study of three PMs in the Saudi Haili dialect. Again, the relevance-theoretic approach was also the framework of analysis adopted by the researcher. For the purpose of deciding whether the three Haili PMs jamaar, maar, and al-muhim should be treated as PMs of Haili Arabic or not, Alshamari has applied Schourup's (1999) characteristics of PMs to the analysis of jamaar, maar, and al-muhim: "connectivity, optionality, non-truth-conditionality, weak clause association, orality, initiality, optionality and multi-categoriality” (p. 6). According to the findings of his study, jamaar, maar and al-muhim are identified as three PMs in the Saudi Haili dialects. For example, jamaar has been identified as a "pejorative or speculative PM with functions related to introducing and signaling "the speaker's attitude against the event at hand," whereas, maar, on the other hand, has three different discursive functions: "logically resultative, contrastive and ironic” PM (p. 7-10). The third PM, “al-Muhim,” has been shown to have one conversational function as an "anti-digression," which basically means to "re-guide" and maintain "the ongoing discussion” on the particular topic (p. 11).

Another study on the Saudi Arabic PMs appeared in Al Rousan (2015)'s study of the Saudi PM maS nafsak, a linguistic element, literary means "be with yourself," which is widely used by young Saudi speakers of different Saudi dialects to communicate various pragmatic functions. The focus of the study was to investigate what pragmatic functions were communicated through the use of this particular marker. For the study, 262 WhatsApp and BBM messages were collected from 17 undergraduate students aged 18-19 at Yanbu University in Saudi Arabia. Out of the 262 messages, a total of 132 cases of the PM maS nafsak occurred in the WhatsApp and BBM conversations among the students.

Based on the qualitative analysis of the students' conversations, 12 pragmatic functions were identified with “context-dependent” functions (Al Rousan, 2015, p. 40) According to the findings of this study, maS nafsak was observed to have meanings that were coded in the consequent utterances, and it can also have "meaning when it occurs on its own" (p. 45). Such a finding opposes the previous studies of Bidaoui (2015) and Alshamari (2015), which regarded PMs as elements with procedural meanings limited to the context. By arguing that the meanings of the PM maS nafsak cannot be limited to the sentence level, and that their different pragmatic meanings are context based, I found Al Rousan's (2015) study to partially align with Aijmer's (2013) argument regarding PM, in which the uses and functions of maY nafsak have been observed as cue phrases "with prosodic and grammatical uses constitute significant information for disambiguating the different meanings and functions of an utterance” (Al Rousan, 2015, p. 45). Therefore, Al Rousan added that the interlocutors have generally used maS nafsak as "a linguistic device to build rapport, to keep the conversation flowing, and to facilitate communication” (p. 46). Briefly, Al Rousan’s (2015) particular treatment of the functions and uses of maS nafsak deals with such linguistic elements as communication devices with functions that are contextually based and meanings that are mediated through interactions; I consider Al Rousan's study to be the basic stone on which my future study will be based. 


\section{Mll Macrothink}

International Journal of Linguistics

ISSN 1948-5425

2018, Vol. 10, No. 2

Based on our discussions of the literature review, it can be clearly indicated that the previous studies on Arabic PMs were mainly based on two different approaches. In the traditional grammarian approach, PMs have been classified as particles with grammatical functions that are limited to sentence level (see Al-Makhzumi, 1964, 1986; Ibn Hišām, 1964). Modern approaches have demonstrated more of a semantic-based analysis where PMs are presented with a wider sematic and pragmatic functions (see Alshamari, 2015). However, the phenomenon is still treated as conjunctions, connectives, and with restricted functions mostly related to the local coherence of texts (e.g. al-Batal, 1985; 1994; Ryding, 2006). In other words, by analyzing Arabic PMs from analytical framework that is based on the relevance theory, PMs are treated as elements only with procedural meanings and functions similar to those of the grammatical categories (See al-Batal, 1994; Basheer, 2016). On the other hand, recent studies on PMs in spoken discourse have succeeded in identifying a wider list of markers and describing multi-functional uses at discourse level. Good examples that clearly present the multi-functionality of those linguistic elements such as the Arabic PMs yaSni /yəSni "I mean" tayyeb, adi "ok" ma؟ nafsak "be with yourself" can be observed in various empirical studies on the phenomena in spoken discourse (see Al Rousan, 2015; Ismail, 2015; Kanakri \& Al-Harahsheh, 2013, etc.).

Yet, when looking at the various analytical frameworks on the phenomena in Arabic literature, it can be noted that the muti-functional uses PMs that have been identified to be "socially, culturally and linguistically embedded in the context" (Aijmer, 2013, p. 9) have not has not yet been enough explored in the previous research. Although the findings of several studies have shown that sociolinguistic variables like gender, age, and social class have a significant impact on the uses and functions of PMs (Zienkowski et. al, 2011, p. 237), this area has not yet attracted the interest of researchers in Arabic linguistics.

Thus, investigating the impact of those important social on the use of Arabic PMs is still another obvious limitation in the Arabic literature. With that being said, conducting a future study with a particular focus on sociopragmatic variations in the uses and functions of Arabic PMs will add a significant contribution to the sociolinguistic aspects, which has been an obvious gap in the literature. Therefore, I strongly believe that conducting a future study that investigates the impacts of the different sociolinguistic variables like gender, age, social class, and region on the functions and uses of PMs will provide us with rich data, which will broaden our understanding of what Arabic PMs are in spoken discourse and help us uncover their multi-functionality perspectives and finally reach more valid conclusions.

\section{Conclusion}

In this literature review on PMs in Arabic spoken discourse, I have discussed the confusion of terminology, different approaches towards the study of PMs in spoken discourse and PMs in Arabic literature. It can be noticed that the factors behind the confusion in the terminological identification and the analysis of the phenomenon are because of various analytical frameworks and researchers' perspectives. Having a valid comprehensive analysis and a broader understanding of what Arabic PMs are in spoken discourse and how they function at discourse level to perform various multiple functions require analytical approach that treats 


\section{MlMacrothink}

International Journal of Linguistics ISSN 1948-5425 2018, Vol. 10, No. 2

PMs as communication devices and also accounts for the multi-functional uses of such linguistic entities that are embedded in interactions.

\section{Acknowledgments}

Although any errors are my own and should not tarnish the reputations of these esteemed persons, I thank Dr. Eva Rodriguez Gonzalez and Mr. Sami Hamdi for comments on the earlier version of this work that greatly improved the manuscript. Also, I would also like to show my gratitude to Dr. Carlos Lopez-Leiva for sharing his pearls of wisdom and expertise with us during the course of this research.

\section{References}

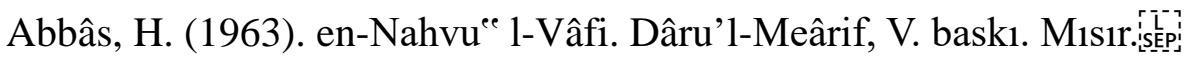

Aijmer, K. (2013). Understanding pragmatic markers: A variational pragmatic approach. Edinburgh, Scotland: Edinburgh University Press.

Aijmer, K., \& Simon-Vandenbergen, A. (2011). Pragmatic Markers. In J. i. Zienkowski, J. Östman, \& J. Verschueren (Eds.), Discursive Pragmatics (pp. 223-247). Amsterdam, Netherlands: Benjamins.

Aijmer, K., \& Simon-Vandenbergen, A. M. (2003). The discourse particle well and its equivalents in Swedish and Dutch. Linguistics, 41(6; ISSU 388), 1123-1162.

Al Kohlani, F. A. (2010). The function of discourse markers in Arabic newspaper opinion articles. (Doctoral dissertation, Georgetown University).

Al Makoshi, M. A. (2014). Discourse markers and code-switching: academic medical lectures in Saudi Arabia using English as the medium of instruction. (Doctoral dissertation, University of Birmingham).

Al Rousan, R. M. (2015). The Use of Discourse Marker “maৎ nafsak” in Saudi Arabic: A Pragmatic Perspective. International Journal of Linguistics, 7(3), 33-48.

Alazzawie, A. (2015). Adi as a discourse marker in spoken Iraqi Arabic. Theory and Practice in Language Studies, 5(7), 1352.

Al-Batal, M. (1990). In a Modern Expository Arabic Text. In Perspectives on Arabic Linguistics: Papers from the Annual Symposium on Arabic Linguistics. Volume II: Salt Lake City, Utah 1988 (Vol. 72, p. 234). John Benjamins Publishing.

Al-Batal, M. (1994). Connectives in Arabic Diglossia: The Case of Lebanese Arabic. In M. Eid, V. Cantarino, K. Walters (Eds.), Perspectives on Arabic Linguistics, VI (pp. 91-119). Amsterdam: Benjamins. https://doi.org/10.1075/cilt.115.10alb

Al-Batal, M. M. A. (1985). The cohesive role of connectives in a modern expository Arabic text. (Doctoral dissertation, University of Michigan.

Alkhalil, T. (2005). Discourse markers in Syrian Arabic: a study of halla', ya' $n$, tayyeb, and lakan. (Doctoral dissertation, University of Essex). 
AL-Makhzumi, M. (1964). Fi al-nahw al-Arabi: Naqid wa tawjeeh. Saydah: Manshurat ALMaktabah AL-Asriya: Beirut.

AL-Makhzumi, M. (1986). Fi al-nahw al-Arabi, 2nd edition. Dar al-Raid al-Arabi: Beirut.

Al-Sayyid, A. A. (1968). Dirasat filllm al-Nahw. Cairo: Dar al-Maarif.

Alshamari, M. R. (2015). 1 A Relevance-Theoretical Account of Three Discourse Markers in North Hail Arabic. Studies in Literature and Language, 11(1), 6-15.

Andersen, G. (2001). Pragmatic markers and sociolinguistic variation. [electronic resource]: a relevance-theoretic approach to the language of adolescents. Amsterdam; [Great Britain]: J. Benjamins, c2001.

Aoun, J., Benmamoun, E., \& Sportiche, D. (1994). Agreement, Word Order, and Conjunction in Some Varieties of Arabic. Linguistic Inquiry, (2), 195-220.

Ariel, M. (1994). Pragmatic operators. The Encyclopaedia of Language and Linguistics. Oxford: Pergamon Press 3250-3253.

Bazanella, C. (1990). Phatic connectives as intonational cues in contemporary spoken Italian. Journal of Linguistics, 14(4), 629-647.

Beeching, K., \& Woodfield, H. (Eds.). (2015). Researching sociopragmatic variability: Perspectives from variational, interlanguage and contrastive pragmatics. Basingstoke: Palgrave Macmillan.

Bidaoui, A. (2015). Discourse Markers of clarification and causality in Maghrebi and Egyptian dialects: a socio-pragmatic perspective (Doctoral dissertation, University of Illinois at Urbana-Champaign).

Blakemore, D. (1987). Semantic constraints on relevance. Oxford: Basil Blackwell.

Blakemore, D. (1992). Understanding Utterances. Oxford: Blackwell.

Blakemore, D. (2002). Relevance and Linguistic Meaning: The Semantics and Pragmatics of Discourse Markers. Cambridge: Cambridge University Press.

Brinton, L. (1996). Pragmatic markers in English: Grammaticalization and discourse functions.

De Fina, A. (1997). An analysis of Spanish bien as a marker of classroom management in teacher-student interaction. Journal of Pragmatics, 28(3), 337-354.

Dér, C. I., \& Markó, A. (2010). A pilot study of Hungarian discourse markers. Language and speech, 53(2), 135-180.

Durán, E. M., \& Unamuno, V. (2001). The discourse marker a ver (Catalan, a veure) in teacher- student interaction. Journal of Pragmatics, 33(2), 193-208.

Erman, B. (1987). Pragmatic Expressions in English. A Study of You know, You see and I mean in Face-to-Face Conversation. Stockholm studies in English, 69, 1-238. 


\section{Mll Macrothink}

International Journal of Linguistics

ISSN 1948-5425

2018, Vol. 10, No. 2

Feng, G. (2010). A Theory of Conventional Implicature and Pragmatic Markers in Chinese. Bingley, UK: Brill NV.

Fischer, K. (Ed.). (2006). Approaches to discourse particles (pp. 1-20). Amsterdam: Elsevier.

Fraser, B. (1988). Types of English discourse markers. Acta Linguistica Hungarica, 38(1/4), 19- 33.

Fraser, B. (1990). An approach to discourse markers. Journal of pragmatics, 14(3), 383-398. 117

Fraser, B. (1999). What are discourse markers? Journal of pragmatics, 31(7), 931-952.

Fraser, B. (2009). An account of discourse markers. International review of pragmatics, 1(2), 293-320. [LE

Fraser, B. (2009). Topic orientation markers. Journal of pragmatics, 41(5), 892-898.

Fung, L. P. Y. (2003). The use and teaching of discourse markers in Hong Kong: students' production and teachers' perspectives (Doctoral dissertation, University of Nottingham).

Fung, L., \& Carter, R. (2007). Discourse markers and spoken English: Native and learner use in pedagogic settings. Applied linguistics, 28(3), 410-439.

Gaddafi, A. M. (1990). Study of discourse markers in Libyan spoken Arabic (Doctoral dissertation, Birkbeck (University of London)).

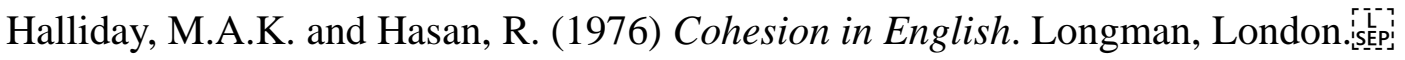

Hellermann, J., \& Vergun, A. (2007). Language which is not taught: The discourse marker use of beginning adult learners of English. Journal of Pragmatics, 39(1), 157-179.

Hussein, M., \& Bukhari, N. (2008). Discourse markers and procedural meaning: The case of fa in standard Arabic. Kashmir Journal of Language Research, 2(16), 116-133.

Ibn Hišām, Abd Allāh ibn Yūsuf. 1964. Muġnī al-labīb, ed. Māzin al-Mubārak, Mu ammad Alī, and Sa ̄̄d al- Afḡān̄i. Damascus: Dār al-Fikr.

Iglesias Moreno, A. E. (2001). Native speaker-non-native speaker interaction: the use of discourse makers. ELIA, 2, 129-142.

Ismail, A. (2015). ab asta'zen ana ba'a: A corpus-based study of three discourse markers in Egyptian film (Doctoral dissertation, The American University in Cairo).

Kanakri, M. A., \& Al-Harahsheh, A. M. (2013). The Discourse Analysis and Pragmatics of? a: di in Jordanian Spoken Arabic. International Journal of English Linguistics, 3(6), 59.

King, Brian. 1992. On the meaning of empty words. Semiotics 89 (1/3): 257-265.

Knott, A., \& Dale, R. (1994). Using linguistic phenomena to motivate a set of coherence relations. Discourse processes, 18(1), 35-62.

Lam, P. W. (2009). The effect of text type on the use of so as a discourse particle. Discourse 
Studies, 11(3), 353-372.

Liao, S. (2009). Variation in the use of discourse markers by Chinese teaching assistants in the US. Journal of Pragmatics, 41(7), 1313-1328.

Long, M. H. (1981). Input, interaction, and second-language acquisition. Annals of the New York academy of sciences, 379(1), 259-278.

Long, M. H. (1983). Linguistic and conversational adjustments to non-native speakers. Studies in second language acquisition, 5(2), 177-193.

Malden, Mass: Blackwell Publishers, 2001. Particle in English Conversation: 'Like, 'Well', 'Y'know'. New York: Garland. (1999). Discourse markers. Lingua, 107(3-4), 227-265.

Maschler, Y. (1998). Rotse lishmoa keta? 'wanna hear something weird/funny [lit.'a segment']?': The discourse markers segmenting Israeli Hebrew talk-in- interaction. Discourse markers: Descriptions and theory, 57, 13.

Miller, S. (2005). Discourse markers in native and non-native English discourse. Amsterdam: Benjamins. 120-121.

Milroy, L., \& Gordon, M. (2008). Sociolinguistics: Method and interpretation (Vol. 13). John Wiley \& Sons.

Nicolle, S. (2000). Markers of general interpretive use in Amharic and Swahili. Pragmatics and Beyond New Series, 173-188.

Östman, J. O. (1995). Pragmatic particles twenty years after. Anglicana Turkuensia, 14, 95-108.

Pichler, H. (Ed.). (2016). Discourse-pragmatic variation and change in English: New methods and insights. Cambridge University Press.

Polanyi, L. and R. Scha (1983). The syntax of discourse. Text 3, 261-70

Quirk, R. S. and G. L. Greenbaum, et al. (1985). A Comprehensive Grammar of the English Language. London: Longman.

Quirk, R. S. and G. L. Greenbaum, et al. (1985). A Comprehensive Grammar of the English

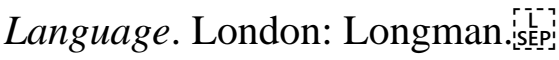

Redeker, G. (1990). Ideational and pragmatic markers of discourse structure. Journal of

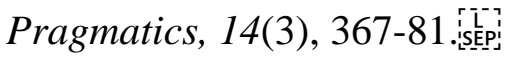

Redeker, G. (1991). Review article: linguistic marker of discourse structure. Linguistics, 29(6), 1139-72.

Redeker, G. (1991). Review article: linguistic marker of discourse structure. Linguistics, 29(6), 1139-72. 'SE'PE]

Ridā, A. (1961). al-Marği'fi l-luġa al-'arab ya. 


\section{Macrothink}

International Journal of Linguistics ISSN 1948-5425 2018, Vol. 10, No. 2

Rido, A. (2010). The use of discourse markers as an interactive feature in science lecture discourse in L2 setting. TEFLIN Journal, 21(1), 90-106.

Rocca, K. A. (2010). Student participation in the college classroom: An extended multidisciplinary literature review. Communication Education, 59(2), 185-213.

Ryding, K. C. (2005). A reference grammar of modern standard Arabic. New York: Cambridge University Press.

Schiffrin, D. (1987). Discourse marker. New York: Cambridge University Press. Schiffrin, D., Tannen, D., \& Hamilton, H. E. (2001). The handbook of discourse analysis.

Shloush, S. (1998). A Unified Account of Hebrew bekicur 'in short': Relevance Theory and Discourse Structure Considerations. Discourse markers: Descriptions and theory. Amsterdarn: John Benjamins, 61-82.

Sinclair, J. M., \& Coulthard, R. M. (1975). Towards an Analysis of Discourse. Oxford: Oxford University Press

Sperber, D., \& Wilson, D. (1995). Relevance: Communication and Cognition. Oxford: Blackwell.

Stanley, P., \& Stevenson, M. (2017). Making sense of not making sense: Novice English language teacher talk. Linguistics and Education, 38, 1-10.

Stubbs, M. (1983). Discourse Analysis. Chicago: The University of Chicago Press.istepi Kendall, S., \& Tannen, D. (2001). Discourse and gender. The handbook of discourse analysis, 548-567. sépiten Have, P. (2007). Doing conversation analysis: A practical guide. London: Sage.în

Trillo, J. R. (2002). The pragmatic fossilization of discourse markers in non-native speakers of English. Journal of pragmatics, 34(6), 769-784.

Tsai, P. S., \& Chu, W. H. (2017). The Use of Discourse Markers among Mandarin Chinese Teachers, and Chinese as a Second Language and Chinese as a Foreign Language Learners. Applied Linguistics, 38(5), 638-665. [iche]

van Dijk, T. A. (1979) Pragmatic connectives. Journal of Pragmatics, 3, 447-456.

Vaskó, I. (2000). The interplay of Hungarian de (but) and is (too, either). In T. Fretheim, and G. Andersen (Eds.), Pragmatic markers and propositional attitude (pp. 255-263). Amsterdam: Benjamins.

Verschueren, J. (1999). Understanding pragmatics. Oxford University Press.sêpiWalsh, S. (2006). Investigating classroom discourse. London and New York: Routledge.

Yang, S. (2014). Investigating discourse markers in Chinese college EFL teacher talk: a multi- layered analytical approach. (Doctoral dissertation, Newcastle University).

Zienkowski, J., Östman, J. O., \& Verschueren, J. (Eds.). (2011). Discursive pragmatics (Vol. 8). John Benjamins Publishing. 


\section{Macrothink}

International Journal of Linguistics ISSN 1948-5425 2018, Vol. 10, No. 2

Ziv, Y. (1998). Hebrew Kaze as discourse marker and lexical hedge: conceptual and procedural properties. Pragmatics and Beyond New Series, 203-222.

\section{Copyrights}

Copyright for this article is retained by the author(s), with first publication rights granted to the journal.

This is an open-access article distributed under the terms and conditions of the Creative Commons Attribution license (http://creativecommons.org/licenses/by/4.0/) 